Mariana Barcinski ${ }^{1}$ Bibiana Altenbernd ${ }^{1}$ Cristiane Campani ${ }^{1}$

\section{Entre cuidar e vigiar: ambiguidades e contradições no discurso de uma agente penitenciária}

Between caring and monitoring: ambiguities and contradictions in the discourse of a female penitentiary officer

\begin{abstract}
The scope of this paper was to establish how the discourse of a female penitentiary officer working in a prison for women reflects, in different ways, the inherent contradiction of prisons, namely their double mission of punishing and resocializing criminals. The data collected in a female prison in Rio Grande do Sul were evaluated using Critical Discourse Analysis, which seeks to understand how discursive productions reflect social power relations. The analyses show that this officer's practice is based simultaneously on punitive and resocializing ideologies, expressed in contradictory feelings of anger and affection towards incarcerated women. Results point to the centrality of gender in the relationship established between officers and interns. Thus, the fact of being a female officer caring and monitoring other women makes this daily relationship even more complex. This complexity extrapolates the limits imposed by prisons.
\end{abstract}

Key words Gender, Prison, Penitentiary officer
Resumo O artigo tem como objetivo verificar de que modo o discurso de uma agente penitenciária que trabalha com mulheres encarceradas reflete de formas diversas a contradição inerente à instituição prisão, a saber, sua dupla missão de punir e ressocializar criminosos. Os dados coletados em uma penitenciária feminina do Rio Grande do Sul foram analisados através da Análise Crítica do Discurso, que tem como objetivo entender de que forma as produções discursivas refletem relações sociais de poder. A análise nos mostra que a prática desta agente fundamenta-se simultaneamente em ideologias punitivas e ressocializadoras, expressas em sentimentos contraditórios de raiva e carinho em relação às detentas. Os resultados nos apontam para a centralidade de gênero na relação estabelecida entre agentes e presas. Portanto, o fato de ser uma agente mulher cuidando e vigiando outras mulheres dota esta relação cotidiana de uma complexidade ainda maior, que extrapola os limites impostos pela prisão.

Palavras-chave Gênero, Prisão, Agente penitenciária
${ }^{1}$ Faculdade de Psicologia, Pontifícia Universidade Católica do Rio Grande do Sul. Av. Ipiranga 6681 Parternon. 90.619-900

Porto Alegre RS Brasil mariana.barcinski@pucrs.br 


\section{Introdução}

Em pesquisa realizada durante cinco anos em unidades penitenciárias femininas no Rio de Janeiro e em Porto Alegre, entrevistamos mais de 30 mulheres sentenciadas pelo crime de tráfico de drogas. O objetivo era compreender o processo de construção da identidade destas mulheres, cujas trajetórias eram marcadas pelo envolvimento em uma atividade criminosa tradicionalmente masculina. No centro das análises propostas estavam questões de gênero, adotadas como marcador fundamental para o entendimento das motivações femininas para a entrada no tráfico, dos papéis usualmente desempenhados por elas na atividade e das características específicas de instituições penitenciárias para mulheres ${ }^{1,2}$.

Em todas as unidades pesquisadas, além das entrevistas com as presas, a pesquisa previu a condução de outras com as agentes penitenciárias encarregadas da vigilância das detentas. A intenção com tais entrevistas era entender, a partir da perspectiva destas profissionais, as especificidades das unidades penitenciárias femininas e do trabalho com mulheres em situação de encarceramento. Embora as agentes entrevistadas servissem como informantes privilegiadas sobre a dinâmica destas instituições, suas histórias nunca se configuraram como foco central de interesse da pesquisa.

No entanto, as entrevistas com as agentes trouxeram à cena uma personagem complexa, negligenciada pelos objetivos originais da pesquisa. Assim como na compreensão das trajetórias de vida das detentas, as questões de gênero pareciam marcar de forma única os relatos das agentes. Afinal, tratava-se de mulheres cuidando/vigiando mulheres, desempenhando uma função igualmente associada ao masculino em suas características de controle, agressão e violência.

Além do interesse específico pelo trabalho das agentes e pelas relações estabelecidas por estas profissionais dentro das prisões, as entrevistas suscitaram o interesse pelas dinâmicas estabelecidas em uma instituição total. Portanto, a análise das entrevistas com as agentes evidenciou uma personagem marcada por profundos conflitos. Seus relatos refletiam simultaneamente as especificidades de uma instituição de controle e vigilância e o estigma associado às suas funções. Foi justamente o reconhecimento da complexidade presente na constituição das identidades das agentes penitenciárias que motivou o presente estudo.

Em relação às entrevistas conduzidas, chamou-nos a atenção o caráter contraditório das suas histórias, dos seus posicionamentos frente às presas e em relação às suas atribuições profissionais cotidianas. Os relatos que versavam sobre a relação estabelecida com as presas expressavam sentimentos contraditórios de raiva e impaciência, por um lado, e de empatia e proximidade desenvolvidas no contato diário com estas mulheres, por outro lado. Da mesma forma, a descrição de suas atribuições oscilava entre funções estritamente de controle e vigilância e a expectativa (mais ou menos explícita) de atuarem como agentes em processos ressocializadores. Tais relatos revelavam, portanto, uma percepção confusa de seu papel como agente, como alguém que simultaneamente deveria (ou desejaria) controlar e vigiar as presas e atuar de forma humanizada na consecução do objetivo de ressocialização das mesmas. Esta confusão se expressava diariamente nas práticas profissionais das agentes.

Diante de tão claras contradições, percebemos que seria inevitável falar delas sem uma análise histórica da instituição prisão. Começamos a conjecturar que os dilemas refletidos no discurso das agentes sobre as suas práticas e os seus sentimentos em relação às presas fossem, em parte, resultado da inserção em uma instituição igualmente contraditória em suas funções. Parecia-nos que os conflitos expressos pelas agentes em tantos níveis de sua atividade cotidiana eram o reflexo de uma instituição que tem o promulgado duplo objetivo de vigiar/controlar/punir e ressocializar sujeitos à margem da sociedade. A pergunta que começou a nos perseguir era, portanto, como a uma mesma instituição ou a um mesmo profissional podem ser atribuídas as funções aparentemente opostas de controle e ressocialização?

$\mathrm{O}$ presente artigo pretende investigar a percepção de uma agente penitenciária acerca de suas atribuições, focando nos possíveis dilemas vivenciados como resultado de discursos institucionais e sociais contraditórios sobre suas práticas. No centro de tal investigação estão questões de gênero, que permeiam as experiências das agentes, especialmente na realidade específica de cuidarem e vigiarem outras mulheres. É de se esperar que o possível entendimento conflituoso sobre suas práticas seja intensificado ainda pelo fato de esta agente ser mulher em convívio diário com outras mulheres, as quais deve vigiar, disciplinar e ressocializar, somente para citar algumas de suas funções instituídas.

\section{A instituição prisão}

Segundo Foucault ${ }^{3}$, o sistema jurídico é historicamente reconhecido por embasar a sua ação 
em um método coercitivo a serviço da defesa pública, da punição e da correção de transgressores da norma social. Até o final do século XVII e início do século seguinte, a coerção corretiva expressava-se pelo castigo físico, através da exposição da dor e da humilhação pública do criminoso. Os suplícios eram realizados como um espetáculo, com ao menos dois objetivos bem definidos: a reconstrução da ordem social violada, através da humilhação do castigado, e a aprendizagem da audiência por observação.

O fim do espetáculo dos suplícios dá lugar aos procedimentos disciplinares que marcam a reforma do sistema punitivo nos séculos XVIII e XIX. A suposta humanização das punições, expressa pelo fim dos castigos públicos, é impulsionada pela percepção da compaixão popular gerada pelos suplícios. O condenado, exposto à violência extrema dos suplícios, passava a ser enxergado publicamente como um herói redimido. Quanto ao carrasco, aquele que infligia o castigo ao condenado, a brutalidade dos seus atos tornavam-no igual ou mais violento que a pessoa criminosa que deveria ser punida ${ }^{3}$.

O corpo flagelado, então, dá lugar a formas mais veladas de controle das transgressões, através do isolamento e da privação de liberdades e direitos, papéis então destinados às prisões. É a condenação, não o sofrimento público, que marca o criminoso, desonerando a justiça do papel desconfortável da punição. A pena imposta pelos juízes magistrados tem a declarada função de reeducar e corrigir, não a de punir. Esta última função, entendida como inglória e vergonhosa, é assumida pela instituição prisão e seus administradores.

O surgimento da instituição disciplinar estabelece como função do poder político a reinserção do criminoso na sociedade, corrigindo e normatizando o seu comportamento. Segundo Yen$\mathrm{do}^{4}$, o direito penal assume a função social de ressocialização destes indivíduos.

A punição, não mais exercida diretamente sobre o corpo físico, tem a finalidade de corrigir, reinserir socialmente e curar. A reclusão, a privação e a despersonalização decorrentes do modelo materializado pelas prisões camuflam o sofrimento corpóreo outrora expresso pelos suplícios. A violência incorpórea expressa pela punição prisional tem seus maiores efeitos na aniquilação e na homogeneização dos sujeitos ${ }^{5}$, advindos do processo de aculturação, através do qual o detento incorpora os hábitos e as normas da prisão ${ }^{6}$. A violência, outrora exercida sobre os corpos, atua de maneira não menos agressiva anulando os desejos e as volições pessoais? ${ }^{7}$.
Ainda sobre os efeitos da prisão contrários ao seu objetivo ressocializador, Baratta ${ }^{8}$ afirma que o cárcere opera no detento um processo de socialização negativa ou "desculturação". O impacto da incorporação da cultura prisional geraria no detento uma "desadaptação" às condições necessárias à sua efetiva ressocialização. Tal suposição sustenta grande parte dos argumentos contrários às políticas de controle social em seu pseudoideal de ressocialização.

É importante notar que a punição prescrita com o aprisionamento ainda hoje inclui castigos direcionados ao corpo do apenado, como a permanência em celas de isolamento e a privação sexual a partir do não atendimento ao direito à visita íntima, por exemplo. O castigo corporal, portanto, que deve física e simbolicamente marcar a separação entre os criminosos e os "homens de bem", desde sempre fez parte do sistema punitivo prisional.

A história da prisão, do flagelo dos castigos à suposta missão humanizadora das prisões, que pretende corrigir e normatizar os detentos para que se tornem aptos ao convívio social, delineia um cenário de ambiguidade acerca do papel atual desta instituição. Fundamentada em sua missão transformadora dos sujeitos, a prisão, com sua "maquinaria carcerária", atua a partir da lógica da coerção e da subordinação. É a partir das contradições e ambiguidades expressas na história e na reconhecida dupla missão das instituições prisionais - punir e corrigir -, que discorremos abaixo sobre a igualmente ambígua função do agente penitenciário.

\section{O papel do agente: entre punir e ressocializar}

Sobre os aspectos históricos associados à função dos agentes penitenciários, Lopes ${ }^{9}$ afirma que a vigilância, a agressão e as torturas como mecanismos disciplinadores para punir e manter a ordem social foram desempenhadas no decorrer da história pelos carrascos, carcereiros, guardas e, atualmente, agentes de segurança penitenciária. A essência do trabalho de vigilância manteve-se praticamente a mesma, porém as denominações foram se modificando no decorrer do tempo: o carcereiro passou a ser o guarda e o guarda tornou-se o agente.

Quanto aos registros históricos, o estudo de Nery ${ }^{10}$ mostra que em 1833, no Brasil, o Decreto Federal $\mathrm{s} / \mathrm{n}^{\circ}$ estipulava critérios para a nomeação de carcereiros das cidades do Império. Conforme os registros encontrados, os funcionários 
do sistema prisional sempre enfrentaram dificuldades e condições precárias de trabalho, o que resultaria na necessidade de especializar estes indivíduos para o desempenho de funções. Por isso, ainda de acordo com Nery ${ }^{10}$, em 1973 no estado do Rio Grande do Sul, houve a criação da Superintendência dos Serviços Penitenciários (SUSE$\mathrm{PE}$ ), para que os Agentes Penitenciários pudessem ser qualificados profissionalmente. Entretanto, a profissão continua caracterizada por antigos problemas, tais como os riscos no trabalho, a insalubridade e a falta de valorização social. É esta realidade que baseia a luta dos agentes por uma formação que possa qualificá-los para atender às demandas do trabalho na situação de cárcere. Neste sentido, a Lei Complementar $\mathrm{n}^{\circ}$ 13.259 de 2009, do Estado do Rio Grande do Sul ${ }^{9,11}$, decreta como qualificação essencial para o recrutamento do Agente Penitenciário a escolaridade de nível superior. Esta recente mudança reflete as reivindicações de quem trabalha no sistema e que continua desempenhando atribuições semelhantes às dos carcereiros de outras épocas, mas que percebe a necessidade de transformação e de preparo para as funções que realiza, especialmente para torná-las mais condizentes ao ideal ressocializador do sistema prisional.

Para investigarmos a complexidade e a incoerência que caracterizam a relação entre o que está prescrito e o que se materializa na prática dos agentes penitenciários, podemos partir da análise da legislação acerca de suas atribuições. A lei referida acima, que dispõe sobre o quadro de servidores penitenciários do Estado do Rio Grande do Sul, define as funções do agente penitenciário e de outros servidores do sistema.

Dentre estas atribuições, aquelas relacionadas aos objetivos de vigilância e controle do efetivo carcerário ficam mais evidentes no texto da legislação. Como exemplo, podemos elencar as seguintes designações: realizar custódia, escolta, disciplina e segurança dos presos; realizar as rondas das alas, galerias, alojamentos, celas, pátios e outras dependências de estabelecimentos prisionais; informar às autoridades competentes sobre as ocorrências; efetuar o controle e a conferência diária da população carcerária em todas as áreas do estabelecimento prisional; supervisionar e fiscalizar o trabalho prisional e a conduta dos presos; realizar os atos e procedimentos das infrações disciplinares.

Nas atribuições acima descritas, a ênfase recai em atividades cujo objetivo é a manutenção da ordem e da segurança das prisões. Tal objetivo expressa-se na legislação através da referência explícita a termos como controle, vigilância, custódia, supervisão e fiscalização.

Algumas atribuições descritas nesta mesma legislação são menos explícitas quanto às expectativas sobre o papel do agente penitenciário, deixando margem à interpretação sobre a forma como estas atribuições devem se expressar na prática. São exemplos destas funções ambíguas descritas na lei: assistir, orientar e acompanhar as ações de tratamento penal nos aspectos de atenção e preventivos para socialização do preso e orientar e realizar trabalhos [...] para instruir os presos em hábitos de higiene, educação e de boas maneiras, despertando o senso de responsabilidade, de dedicação no cumprimento dos deveres familiares, profissionais e sociais $^{11}$.

A falta de clareza do que seria, na prática, o cumprimento de suas atribuições resulta em um entendimento parcial e fragmentado por parte do agente na sua implícita responsabilidade (re)socializadora. Além disto, uma análise acurada da descrição de tais funções nos faz questionar acerca do preparo deste profissional para o pleno exercício delas. Que tipo de formação e de perfil garantiria a um profissional a habilidade e a legitimidade de atuar, por exemplo, como modelo inspirador do "senso de responsabilidade" dos detentos?

No cumprimento de suas funções, portanto, o agente executa serviços de vigilância e custódia, aplica medidas restritivas de direitos e de privação de liberdade, bem como atua na execução de programas e ações de apoio ao tratamento penal para socialização dos detentos. As atribuições prescritas reforçam a confusão do papel do agente penitenciário, que provavelmente reflete a própria falta de clareza sobre a dupla função - punitiva e ressocializadora - da instituição penitenciária. Como ressocializar a partir do isolamento, do rompimento de laços afetivos e sociais ${ }^{12}$ ou de práticas punitivas que revitimizam os presos constantemente dentro destas instituições?

\section{$O$ agente estigmatizado}

Lourenço ${ }^{13}$, ao discutir a subjetividade dos agentes penitenciários, nos fala do seu duplo estigma. Para a sociedade o agente é desacreditável, visto como um sujeito potencialmente corruptível, dada a sua proximidade cotidiana com a delinqüência e a marginalidade. Por outro lado, para o preso, o agente é desacreditado e desvalorizado, por personificar os objetivos institucionais de vigilância e controle e com quem o preso tem que forçosamente conviver em uma relação de 
submissão. No Brasil, a dimensão contemporânea desta dicotomia entre agentes e internos é bem detectada por Coelho ${ }^{14}$, que em um trabalho pioneiro sobre o sistema prisional afirmava que "(...) efetivamente o guarda (agente) representa e simboliza tudo o que oprime o preso, ou tudo o que o preso experimenta, como negligência, frustração, carência e opressão".

Neste sentido, trabalhar na prisão é comumente retratado de forma depreciativa e o estigma vivenciado pelos agentes impacta intensamente a sua vida e as suas possibilidades de interação social. $\mathrm{O}$ agente possui um traço que o marca; ele é um elemento suspeito, que chama a atenção e desperta a curiosidade de outros. Sua condição profissional tem o potencial de afastá-lo dos outros e de desviar o foco da atenção alheia para outros de seus atributos, não diretamente vinculados ao seu exercício profissional.

A discrição dos agentes acerca do que praticam e do que presenciam no cotidiano da prisão significa a possibilidade de encobrimento do estigma que carregam. Sua prática profissional constrói a sua identidade e, diante do estigma a ela associada, não convém que seja compartilhada em outros contextos sociais. Segundo Goff$\operatorname{man}^{15}$, o encobrimento do estigma é utilizado por pessoas que despendem esforços para passarem despercebidas, por terem alguma posição que não é gratificada socialmente ou pelo fato de o estigma do indivíduo estar relacionado a fatores que não deveriam ser divulgados a estranhos.

No que se refere aos impactos à saúde do agente, dificuldade para dormir e evitação de contato com multidões são exemplos de como as possibilidades de lazer, interação social e qualidade de vida são influenciadas pela preocupação intensa e recorrente com a violência. Portanto, esta é uma profissão considerada arriscada e estressante, marcada pelo risco à integridade física e moral, bem como pela vulnerabilidade, já que esses sujeitos podem ser reconhecidos pelos seus nomes e rostos, tanto dentro quanto fora dos muros do presídio ${ }^{13}$.

\section{Método}

Este trabalho configura-se como um estudo de caso, método que nos permite alcançar uma descrição profunda do fenômeno pesquisado, a saber, o cotidiano profissional de uma agente penitenciária e o significado atribuído por ela a este cotidiano. Segundo Stake ${ }^{16}$, o estudo de um caso particular tem o potencial de nos auxiliar na com- preensão de um fenômeno mais amplo, fornecendo insights para generalizações futuras.

A escolha do caso presente se deve por acreditarmos que o conteúdo da entrevista conduzida com a agente reflete, de formas diversas, os conflitos teorizados sobre suas atribuições profissionais. Além disto, a entrevistada apresenta uma postura crítica em relação à sua atuação, em particular, e sobre a atuação das agentes penitenciárias, em geral.

A entrevista ora analisada foi realizada em 2012 em uma penitenciária feminina de Porto Alegre. À época, a instituição contava com cerca de 250 presas $^{17}$, a maior parte delas sentenciada pelo crime de tráfico de drogas.

A agente penitenciária entrevistada tem 32 anos e realiza atividades que demandam o contato direto com as detentas diariamente. À época da entrevista, Fabiana (nome fictício) atuava como agente penitenciária há apenas um ano, o que em parte pode justificar a postura crítica que ela apresenta sobre a prática das agentes na sua instituição. Além disso, e em contraste com grande parte das mulheres atuando como agentes, ela possui curso de nível superior. Fabiana trabalha na ala materno infantil da unidade prisional, local escolhido por ela pela possibilidade de estabelecer um contato mais direto com as presas, já que ali as internas circulam livremente.

A entrevista conduzida com a agente durou cerca de duas horas. Contou com um protocolo de perguntas, conduzidas de maneira flexível, com o objetivo de que as histórias narradas fossem desenvolvidas com o mínimo de constrangimento. Tais perguntas versaram sobre a trajetória pessoal e profissional da agente, focando nos dilemas vivenciados em sua prática profissional.

O objetivo da entrevista foi propiciar à agente a possibilidade de relatar os eventuais dilemas decorrentes das especificidades de sua profissão. A partir dos conflitos vislumbrados na própria descrição das suas atribuições, esperávamos que o seu discurso fosse marcado por ambiguidades e contradições, especialmente ao versar sobre seu cotidiano profissional.

Desta forma, buscou-se oferecer um espaço para que Fabiana pudesse narrar a forma como atua, os sentimentos que emergem desta atuação e as contradições vivenciadas, tendo em vista o papel que lhe é atribuído no contexto carcerário, papel que oscila entre a punição e a ressocialização, como discutido anteriormente. A entrevista foi gravada em áudio, com o consentimento da participante e transcrita para a análise discursiva proposta no estudo. 
Para a análise dos dados coletados, utilizamos como instrumento de investigação a Análise Crítica do Discurso, que tem como objetivo compreender a forma como se dá a relação entre discurso e poder ${ }^{18}$. Por meio do referido instrumento, buscamos entender as práticas discursivas como modos de ação historicamente situados. Nesta perspectiva, o discurso é moldado pela estrutura social e vice-versa ${ }^{19}$.

Segundo Fairclough ${ }^{20}$, o discurso deve ser compreendido como forma de prática social, não como uma produção individual, evidenciando a relação dialética entre discurso e estrutura social. É neste sentido que devemos compreender que o discurso produzido na situação de entrevista por uma agente penitenciária, por exemplo, refletirá o contexto institucional ocupado por ela e no qual desempenha suas atividades.

O presente estudo tem como objetivo compreender aspectos sociais e políticos que emergem dos discursos "individuais" produzidos na entrevista. Assim, o discurso da agente deve ser contextualizado, a partir de aspectos sociais ligados à função por ela exercida, dos constrangimentos institucionais e das relações de poder que emergem em uma instituição total como a prisão.

\section{Resultados}

Os dados provenientes da entrevista foram agrupados em duas categorias interpretativas, que refletem a fundamentação teórica que sustenta o estudo. Visto que o objetivo era entender as ambiguidades presentes no discurso da agente penitenciária acerca da sua prática profissional, as categorias foram constituídas por pares de conceitos opostos. Estes pares refletem as contradições expressas no discurso, enfatizando o caráter dilemático da construção discursiva da participante. Os resultados da análise são discutidos abaixo, após uma breve síntese dos elementos que compõem cada categoria interpretativa proposta.

\section{Cuidar $\mathrm{x}$ vigiar}

Nesta categoria estarão os trechos de discurso em que a participante expressa as ambiguidades acerca das suas atribuições como agente, ora entendidas como ligadas ao cuidado e à ressocialização, ora definidas exclusivamente como atividades de controle. A apropriação de discursos contraditórios sobre suas funções é expressa em falas ambíguas sobre o seu exercício profissional. Em parte, a entrevistada se apropria de um dis- curso institucional, que prescreve o controle, a violência, a neutralidade e o distanciamento emocional no exercício profissional. Neste sentido, seu discurso enfatiza a assimetria na relação com as presas, bem como a necessidade de que a distância entre elas seja marcada no exercício de suas práticas. Em contraste, a participante se apropria de um discurso redentor, que expressa a crença no caráter ressocializador das suas atividades. Imbuída deste espírito, seu discurso é caracterizado pela preocupação em estabelecer relações mais humanas e próximas com as presas.

Ao ser questionada sobre as especificidades do trabalho com detentas grávidas ou com as que têm com elas seus filhos recém-nascidos, Fabiana justifica a sua escolha por trabalhar na ala materno-infantil. Poucas agentes escolhem trabalhar neste local, segundo ela, pela dificuldade em lidar com mulheres grávidas e com filhos recém-nascidos. A maior destas dificuldades seria o julgamento moral, por parte das agentes, de internas que manifestam o desejo de ter com elas seus filhos durante o período de cumprimento de suas sentenças.

eu preferi ficar na feminina pra ser mais próximo da realidade que eu queria encontrar [...] masculino tu tá mais distante, [...] não tem como tu manter uma relação mais humana.

Trabalhar em uma penitenciária feminina significa para ela a possibilidade de estabelecer uma relação mais humana com a população carcerária, possibilidade que ela não vislumbra no trabalho com homens presos. Portanto, o caráter humano do seu trabalho como agente coloca-se como uma exclusividade do contato com mulheres, deixando implícito o caráter mais agressivo das práticas estabelecidas em instituições prisionais masculinas.

A adoção, como norma, de práticas violentas no trato com presos é sutilmente expressa no trecho a seguir, em que Fabiana individualiza a humanidade da sua própria perspectiva. Ela se distancia de outras agentes, que adotam condutas pouco humanas com as presas, chamando a atenção para a especificidade do seu comportamento. Sua humanidade é, então, descrita como um traço pessoal, fruto da forma como foi socializada, não como uma orientação institucional para a conduta dos agentes.

se tu tem já uma criação assim de perceber o indivíduo, de se colocar no lugar do outro, eu acho que no teu trabalho tu também vai te colocar sempre no lugar do outro.

A empatia descrita como parte da sua conduta é descartada por Fabiana como atribuição 
do cargo de agente penitenciária. Portanto, ao tratar as presas com humanidade e proximidade, ela extrapolaria as suas funções profissionais. $\mathrm{O}$ que poderia ser interpretado como um excesso inadequado da parte dela, no entanto, marca uma vez mais a distância entre Fabiana e outras agentes que não adotam as mesmas condutas em seu cotidiano.

não é minha função, é óbvio, mas já que a gente tá próximo, a gente tenta, ou conversa ou eu digo: 'porque que tu não tenta trabalhar, fazer isso, fazer aquilo', sempre dando um conselho.

O trecho acima é um primeiro exemplo da confusão - recorrentemente expressa no discurso de Fabiana - ao tentar descrever as suas atribuições. Podemos supor que extrapolar as funções legais dos agentes, agindo com empatia com as detentas, seja também resultado do entendimento precário do que sejam as suas atribuições. Tal desconhecimento faz com que ela atue como conselheira e agente ressocializadora, colocando-se em uma posição assimétrica em relação às detentas.

A seguir, a entrevistada discorre sobre a falta de satisfação com o trabalho de agente, o que abre ainda mais uma possibilidade para interpretarmos o fato de ela agir de forma a expandir os limites de suas funções. Cerceada por um trabalho eminentemente de controle, o contato humano com as presas dota este trabalho de uma conotação mais positiva do que ele possa, de fato, ter para Fabiana.

Porque o nosso serviço não é como ser professor. Além do seu salário, o professor tem aquele retorno: tu ensinou uma criança, a criança te retorna com sorriso, com aprendizado. Dentro do sistema prisional, tu não tem esse retorno, há poucos casos que tu vê que saem daqui, que não retornam, que vão trabalhar

O discurso acima é construído claramente para a interlocutora de Fabiana, que se apresenta como professora ao início da entrevista. Neste sentido, seu discurso retoricamente posiciona as duas funções - de professora e de agente - como opostas no que concerne à satisfação por sua execução.

Interessante notar que no trecho acima Fabiana toma para si (para as agentes, de uma maneira geral) a responsabilidade pela reincidência das presas. $\mathrm{O}$ fato de elas retornarem para o sistema prisional, após terem obtido a progressão de regime ou a liberdade definitiva, significa o fracasso do seu trabalho. O retorno profissional, no caso das agentes, seria a "recuperação" das mulheres encarceradas, expressa pelo defini- tivo afastamento da prisão e pela inserção no mundo formal do trabalho.

Se por um lado esta fala expressa a preocupação de Fabiana com o futuro das presas pósencarceramento, por outro ela novamente revela a extrapolação do que seria a função de uma agente. Ao assumir a responsabilidade pela reinserção social das mulheres encarceradas, ela concede à agente um papel mais nobre do que o simples controle das detentas. No trecho abaixo, ela novamente reitera sua função no processo de "redenção" das internas:

tem aquelas que tu pode por uma sementinha, que talvez cresça.

Cabe à Fabiana, ou a outras agentes, de forma individualizada, a função de incutir nas presas algo de positivo que as auxilie em seu processo ressocializador. Cabe a ela, ainda, decidir quem são as presas que merecem tal investimento de sua parte ("aquelas que tu pode por uma sementinha"). Importante notar que a própria instituição prisional tem os seus mecanismos classificatórios das presas, que as posicionam em grupos que merecem ou não o investimento institucional (através da provisão de trabalho e de reais chances de inserção social, por exemplo).

O trecho anterior expressa a ideologia corretiva da instituição prisão. Colocando-se em uma posição moralmente superior às presas, é Fabiana quem tem a missão de socializar estas mulheres, de transmitir conteúdos para que elas façam, então, escolhas de vida acertadas. A seguir, a entrevistada delega esta missão à instituição; a função ressocializadora é agora enfatizada como prerrogativa do sistema prisional.

Mas a gente não tem a garantia de que quando elas vão sair, elas vão usar o que elas aprenderam aqui pra não fazer algo de errado de novo.

Em diversos momentos de sua entrevista, Fabiana problematiza a representação social dos agentes penitenciários. Nestes momentos, seu discurso expressa o estigma associado a este profissional e a forma como ela procura, em sua prática, se afastar dele. A seguir, delimita a distância entre ela (e algumas colegas da "sua geração") e agentes que acreditam que suas práticas devem estar baseadas na agressividade e na coerção das presas.

as colegas usavam a força, na base do grito $[. .$. geralmente era essa a visão e é essa a visão que a sociedade tem, que a gente tem que ser mau, tem que ser agressivo, tem que se usar a força. E essa nova geração nossa de agentes que entrou quando eu entrei, não tem essa visão [...] tem uma visão mais humana, conversando. 
Segundo Fabiana, há uma expectativa social de que os agentes penitenciários sejam "maus", que assumam uma postura agressiva e o uso da força para a manutenção da ordem. Tal expectativa socialmente depositada - e não atendida pelas agentes mais novas e há menos tempo no sistema prisional - justificaria o modo como algumas de suas colegas costumam desempenhar suas funções. A priorização de uma conduta diferenciada com as presas, mais humanizada e baseada no diálogo é, de acordo com a entrevistada, uma prerrogativa da nova geração de agentes penitenciárias. Esta nova geração descrita pela entrevistada é, a partir de 2009, composta por agentes com nível superior de escolaridade, o que talvez explique a diferenciação que ela delineia entre estas e as agentes antigas, especialmente no que concernem suas preocupações humanizadoras.

Se acima Fabiana credita às agentes há mais tempo no sistema a postura rígida e agressiva em relação às presas, abaixo ela responsabiliza a instituição prisão por esta mesma postura. Em diversos momentos ela oscila entre individualizar e institucionalizar as práticas expressas pelas agentes:

o sistema prisional tinha outra visão, [...] quem tá preso não tem direito nenhum e que quem tá do outro lado tem que crucificar o outro.

Ao discorrer sobre a natureza da prática das agentes de "sua geração" - práticas mais humanizadas -, Fabiana menciona a inadequação do afeto demonstrado em relação às presas:

não sou bem vista se eu conversar mais com alguém [com uma presa].

A inadequação das relações pautadas no carinho e no cuidado com as presas é possivelmente gerada pelas expectativas da instituição e da sociedade em relação aos limites de uma convivência entre agentes e presos. Implícita no discurso de Fabiana está a crença de que tal relação deva ser baseada na separação entre estes atores, sendo esta expectativa compartilhada com suas colegas agentes da instituição.

A seguir, o discurso da entrevistada uma vez mais enfatiza a missão ressocializadora da prisão. Neste trecho, Fabiana coloca as presas em uma posição infantilizada - na explícita comparação destas com crianças indisciplinadas -, delegando à instituição prisional a função socializadora e educadora desta população.

Aqui, no meu ponto de vista elas voltam a ser criança. Elas estão aqui porque elas não tiveram disciplina, elas não tiveram uma educação, lá fora, ok. Aquela coisa: falhou a familia, falhou a escola, dai sobrou pra polícia, a polícia pegou, caiu aonde?
O discurso da entrevistada posiciona as detentas em um lugar inferior em uma hierarquia moral e educacional. Neste sentido, cabe às agentes e à instituição prisional o papel normatizador que a sociedade - através das suas outras instituições corretivas - não logrou desempenhar.

\section{Raiva $\mathrm{x}$ carinho}

Resultante igualmente do conflito entre atribuições punitivas e humanizadoras, os discursos que ilustram esta categoria versam sobre os sentimentos das agentes em relação às presas. A admissão do carinho, em geral travestida por princípios humanizadores mais abstratos, é contrastada com a afirmação da necessária assimetria na relação com as detentas. O dilema de experimentar um afeto positivo por alguém a quem se deveria controlar é expresso de formas diversas. Embora adequado do ponto de vista humanitário, o carinho nas relações com as presas é usualmente descrito como inapropriado institucional e socialmente. O discurso de Fabiana expressa ao mesmo tempo a inevitabilidade do vínculo desenvolvido com as detentas e a surpresa de se ver acometida por sentimentos positivos.

Ao tratar do sentimento de raiva causado pela postura de algumas presas da ala materno-infantil, Fabiana constrói um discurso moralizador sobre as internas que usam seus filhos para adquirir benefícios no cárcere, tais como serem transferidas para celas melhores na prisão:

Não são todas, cada caso é um caso, muitas vezes elas usam os filhos pra benefício próprio [...].

Questionada sobre a natureza deste sentimento de raiva e da possibilidade de desenvolver, em seu trabalho, outras formas de afeto em relação às presas, a entrevistada assume a inevitabilidade do carinho e da empatia no desempenho de suas tarefas. Novamente ela se distancia de outras agentes, que possivelmente não se permitiriam vivenciar sentimentos positivos em relação às detentas:

muitas [agentes] vão dizer que não, mas tem. Tu te ternaliza por algumas e começa a entender o porquê que ela tá ali.

A referência à ternura e à empatia situa Fabiana em uma posição diferenciada em relação às demais agentes, para as quais a função deve estar essencialmente ligada ao controle das detentas. Seu discurso tem, portanto, o efeito retórico de marcar a sua especificidade em comparação às colegas no sistema prisional.

Ao relatar o episódio em que teve que efetuar a transferência de três presas e seus bebês para 
outra penitenciária, Fabiana evidencia surpresa ao se perceber acometida por sentimentos de carinho e saudades.

A gente levou três, não tinha mais aquelas três presas e não tinha mais aquelas três crianças, e eu me dei por conta, assim, que eu tinha me afeiçoado, que eu tinha me acostumado, acho que é uma forma de afeto, né?

$\mathrm{O}$ fato de as presas, pelas quais Fabiana admite ter um sentimento positivo, serem mães e terem com elas seus bebês na prisão talvez faça desta admissão de carinho uma tarefa mais fácil para a entrevistada. Deste modo, a falta sentida quando da transferência das presas é dirigida especificamente para seus bebês, sentimento que é potencialmente mais aceito pelas outras agentes e por ela própria, além de socialmente mais compreensível.

Abaixo Fabiana relata abertamente a surpresa por se ver acometida por tais sentimentos:

Nesse dia, assim, eu percebi que eu tinha criado um afeto, e dai eu pensei 'meu Deus e agora? Isso é certo, isso é errado?'.

O trecho é rico pelo caráter explícito da surpresa da agente e pela sua inabilidade em lidar com este sentimento. Seu discurso individual traz a marca de outro hegemônico, mais amplo, segundo o qual o carinho, as saudades e a falta são sentimentos não legitimados institucional e socialmente entre agentes e presas.

\section{Conclusão}

O presente estudo tinha como objetivo ilustrar através de dados empíricos o caráter dilemático das práticas de uma agente penitenciária de uma instituição prisional feminina. Como as análises demonstram, as marcas de uma prática penal punitiva se fazem sentir atualmente no trabalho da agente, mesmo que sua prática hoje seja revestida de um ideal promulgado de ressocialização. Portanto, práticas e ideologias punitivas e educativas convivem no cotidiano e no discurso da entrevistada.
As análises focaram-se, ainda, nas questões de gênero que complexificam o cotidiano profissional de agentes mulheres trabalhando em unidades prisionais femininas. Os dados nos mostram que o fato de as agentes serem mulheres, punindo, controlando, vigiando e educando outras mulheres, dota esta relação de um caráter peculiar. O contato cotidiano com as presas promove o cenário propício para o desempenho das funções de cuidado e educação - socialmente atribuídas às mulheres -, bem como para abusos de poder e dominação.

A centralidade de gênero no discurso da agente entrevistada nos remete às especificidades do trabalho com mulheres encarceradas. As unidades prisionais femininas não são preparadas, em suas estruturas ou em suas dinâmicas, para lidar com tais especificidades. Da mesma forma, as agentes que lidam diretamente com mulheres presas não são capacitadas para lidar com as complexidades da empreitada, especialmente no que se refere ao entendimento do processo singular de constituição da subjetividade feminina. Portanto, o trabalho aqui apresentado nos aponta para a necessidade de propormos ações e iniciativas de capacitação e sensibilização das instituições e dos profissionais do sistema prisional em contato direto com mulheres encarceradas.

\section{Colaboradores}

M Barcinski, B Altenbernd e C Campani participaram igualmente de todas as etapas de elaboração do artigo. 


\section{Referências}

1. Barcinski M. Protagonismo e vitimização na trajetória de mulheres envolvidas na rede do tráfico de drogas no Rio de Janeiro. Cien Saude Colet 2009; 14(2):577-586.

2. Barcinski M. Centralidade de gênero no processo de construção da identidade de mulheres envolvidas na rede do tráfico de drogas. Cien Saude Colet 2009; 14(5):1843-1853.

3. Foucault M. Vigiar e Punir: Nascimento da prisão. 36a ed. Petrópolis: Vozes; 2009.

4. Yendo SA. Da punição à ressocialização. Intertemas 2007; 14(14):7.

5. Goffman E. Manicômios, Prisões e Conventos. São Paulo: Perspectiva; 2001.

6. Thompson AFG. A Questão Penitenciária. Petrópolis: Forense; 1980.

7. Fonseca KP. Re(Pensando) o crime como uma relação de antagonismo entre seus autores e a sociedade. Psicologia: ciência e profissão 2006; 26(4):532547.

8. Baratta A. Criminologia Crítica e Crítica do Direito Penal. Introdução à Sociologia do Direito Penal. Rio de Janeiro: Revan; 2002.

9. Lopes R. Psicologia Jurídica O Cotidiano da Violência: O trabalho do Agente de Segurança Penitenciária nas Instituições Prisionais. Psicología para América Latina. [periódico na Internet]. [acessado 2013 jun 18]:[cerca de 8 p.]. Disponível em: http:/ /psicolatina.org/Cero/psicologia_juridica.html

10. Nery TRA. Da ética à poética do ser servidor penitenciário. Porto Alegre: Companhia Rio-Grandense de Artes Gráficas; 2012.

11. Rio Grande do Sul. Lei Complementar $n^{\circ} 13.259$, de 20 de Outubro de 2009, do Estado do Rio Grande do Sul. Dispõe sobre o Quadro Especial de Servidores Penitenciários do Estado do Rio Grande do Sul, da Superintendência dos Serviços Penitenciários - Susepe -, criado pela Lei $n^{\circ} 9.228$, de $1^{\circ}$ de fevereiro de 1991, e dá outras providências. Diário Oficial do Estado do Rio Grande do Sul 2009; 21 out.
12. Wacquant L. A Aberração Carcerária à Moda Francesa. Dados rev. ciênc. sociais. 2004; 47(2):215-232.

13. Lourenço LC. Batendo a tranca: Impactos do encarceramento em agentes penitenciários da Região Metropolitana de Belo Horizonte. Dilemas, Rev. de Estud. Conflito Controle Soc. 2010; 3(10):11-31.

14. Coelho EC. A oficina do diabo: e outros estudos sobre criminalidade. Rio de Janeiro: Record; 2005.

15. Goffman E. Estigma: notas sobre a manipulação da identidade deteriorada. Rio de Janeiro: LTC; 2008.

16. Stake RE. Case studies. In: Denzin NK, Lincoln YS, editors. Handbook of qualitative research. London: Sage; 2000. p. 435-454.

17. Brasil. Ministério da Justiça. Departamento Penitenciário Nacional. Mulheres Presas - Dados Gerais. Brasília: Ministério da Justiça; 2011.

18. Van Dijk TA. Discurso e poder. São Paulo: Contexto; 2008.

19. Resende VM, Ramalho V. Análise de discurso crítica. São Paulo: Contexto; 2006.

20. Fairclough N. Discurso e mudança social. Brasília: UNB; 2008.

Artigo apresentado em 20/06/2013

Aprovado em 30/07/2013

Versão final apresentada em 13/08/2013 